\title{
Trees outside Forests
}

Trees outside forests include all trees found on non-forest and non-wooded lands, i.e., trees on agricultural lands, in urban and settlement areas, along roads, in home gardens, in hedgerows, scattered in the landscape and on pasture and rangelands. Trees outside forests fulfill diverse environmental, social, cultural and economic roles and various benefits could be obtained through their wider integration in all land-use systems (rural and urban).

In the past decade, agriculture and urban expansion have occurred at the expense of forest, woodland, cropland and grassland ecosystems. The accumulated effects of these changes are reflected in serious soil degradation, desertification and loss of biodiversity, leading to food insecurity and extreme poverty in the most vulnerable areas where food production opportunities have been lost.
Tree planting and management is one of the solutions for addressing these challenges. Trees have the potential to restore degraded ecosystems, to provide food, medicines and other goods and to render environmental services (shade, protection from wind, micro-climate improvement, soil fertility, prevention of soil erosion) and socio-economic benefits and values. Trees outside forests are now recognized as a valuable tool in sustainable development and in enhancing livelihoods, as illustrated by traditional tree-based agriculture and livestock systems developed and practised over centuries by farmers and herders.

The importance of considering trees outside forests as a distinct category of forest resources was first recognized at the FAO/ECE Meeting of Experts on Global Forest Resources Assessment, held in Kotka, Finland in 1993 (Kotka II). Since then, through continuous awareness raising and case studies, FAO has given more visibility to trees outside forests and has dispelled the idea that tree resources are important only for small-scale farmers or that they make only a limited contribution to sustainable forest resource management.

The Global Forest Resources Assessment 2000 (FRA 2000) did not attempt a comprehensive global assessment of trees outside forests, nor has such an assessment ever been made. However, FRA 2000 reviewed available information on trees outside forests for specific countries or land areas and drew attention to the difficulties involved in their assessment. The study revealed a paucity of information about these resources at the national level. FAO is therefore assisting member countries in developing assessment tools and methodologies and in establishing and

\section{Forest Genetics}

The Department of Renewable Resources, Faculty of Agriculture, Forestry and Home Economics, University of Alberta seeks to fill a research/teaching position as an NSERC Industrial Chair in forest genetics and tree improvement. The incumbent will develop a nationally competitive research program in forest genetics serving the needs of forest genetics and tree improvement in Alberta. The applicant should have a PhD in quantitative genetics. Experience in the use of molecular markers in breeding of forest trees is an asset. At least one degree in forestry is desirable, as are experience with breeding programs, forest field research and good knowledge in mathematical statistics. The Faculty emphasizes excellence in teaching: evidence of novel approaches and interest in alternative (nontraditional) teaching methods is desirable. Teaching responsibilities may include courses in undergraduate forest biology and advanced courses in tree improvement in the Forestry program both at the undergraduate and graduate levels. The successful candidate will participate in the Centre for Enhanced Forest Management and may link to the environmental and conservation sciences program. The successful applicant will develop strong linkages with forest industry and provincial government tree improvement and biotechnology research programs. Leadership is expected in the development of collaborative research, teaching and technology transfer activities both within the University and with partners in industry and government in land and resource management.

The position is anticipated for January 1,2005 , following a successful application to the NSERC Industrial Chair Program. The current salary range for an Assistant Professor (Junior Chair) is $\$ 49,188$ to $\$ 69,660$; the salary for a Senior Chair is negotiable. The Selection Committee will begin selection on January 31, 2004. A letter of application, outlining research, teaching, and technology transfer interests, a curriculum vitae, a teaching dossier and names of three referees should be sent to:

\section{Chair}

Department of Renewable Resources

University of Alberta

Edmonton, Alberta T6G 2H1

Additional information about the Renewable Resources Department, the Forestry program and the Environmental and Conservation Sciences program is available from the Department web page at www.rr.ualberta.cal

All applicants are thanked in advance for their interest. Only those selected for interview will be contacted.

All qualified candidates are encouraged to apply; however, Canadians and permanent residents will be given priority. The University of Alberta hires on the basis of merit. We are committed to the principle of equity in employment. We welcome diversity and encourage applications from all qualified women and men, including persons with disabilities, members of visible minorities, and Aboriginal persons. 
improving information systems and networks.

FAO is also helping to raise the profile of trees outside forests and highlight their role in sustainable livelihoods, for example through meetings such as the workshop "Enhancing the Contribution of Trees outside Forests to Sustainable Livelihoods," held in Rome in 2001. These efforts have highlighted a pressing need to develop sound approaches and technologies for promoting trees outside forests worldwide, including strengthening dialogue among stakeholders and building institutional capacities.

Promotion of trees outside forests is a strategic element in FAO's efforts to enhance forestry's contribution to sustainable development and livelihoods. FAO has published several Conservation Guides on the subject, including Agroforesty parklands in sub-Saharan Africa (1999) and Arbres hors forêt-vers une meilleure prise en compte (2001). In addition, six country case studies have been prepared on planted forests, trees outside forests and urban and peri-urban plantations in LFCCs (Ethiopia, the Islamic Republic of Iran, Mali, Namibia, Oman and Tunisia).

\section{Urban and peri-urban forestry}

In recent years, experts and institutions concerned with the sustainable development of cities have paid increasing attention to the potential role of tree planting in landscape structuring, beautification of the urban environment and improvement of health conditions. Brisk expansion of urban populations in developing countries is projected by 2025 , and many settlers will live in poor conditions and will face food insecurity, lack of clean drinking water, inadequate energy for domestic use, shortage of construction material, air pollution and insanitary disposal of waste and sewage. Much of the urban expansion will be on hillsides prone to erosion or in swampy areas. Urban trees hold potential to protect reservoirs from erosion and siltation, to stabilize hilly or sloping areas, to minimize air pollution through carbon sequestration and to generate income. In addition, beautification of cities through tree planting can stimulate investment, develop business and create employment.

FAO's recent work in this area has included country case studies, a spotlight on urban and peri-urban forestry and city greening at the workshop on trees out- side forests in 2001 and participation at many international meetings and workshops on urban forestry.

FAO's strategy for urban and periurban forestry includes assistance to member countries, particularly developing countries, in establishing and managing forests and trees in and around cities, and strengthening of North-South cooperation in technology transfer for urban and peri-urban forestry technology. New thrusts will aim at improved elaboration of planning and management principles and tools to conserve and develop green areas and planted forests.

\section{Technical assistance}

Many developing countries have requested assistance in establishing plantations and managing natural forests in periurban areas for fuelwood production, erosion control, protection of water resources and optimization of the environmental and economic benefits of forests. A number of projects have been or are being developed in member countries, for example:

- implementation of an urban and periurban forestry project for tree planting and forest management in three provinces of Angola;

- preparation and development of urban forestry projects in Cameroon, Mali, Senegal, the Sudan, Tunisia and Uruguay; - preparation of a plan for national tree planting and development of peri-urban forestry using sewage water resources in Egypt.
FAO has also provided assistance through training and study tours for technicians in government and non-governmental organizations (NGOs) regarding urban and peri-urban issues.

\section{Programme support}

Future activities will support strengthening of the capacity of national policymakers and institutions to address the economic, social and environmental issues relating to trees and forests in urban areas and to increase the value of forest and tree cover withing human settlements. Specifically, FAO will:

- support integration of trees within urban and peri-urban agricultural production systems (windbreaks, live fences, fruit-trees, home gardens, orchards, watershed) through training and institutional capacity building;

- increase awareness and understanding of urban and peri-urban forests and parks to mitigate problems related to rapid urbanization processes and migration fluxes, and their impact on land use changes and degradation;

- support regional and international networking and cooperation between developed and developing countries to facilitate exchange of knowledge and information about responses to urban and peri-urban development issues.

For additional information: www.fao.org/forestry/tof

\section{Come visit CIF/IFC at http://www.cif-ifc.org}

\section{read about CIF / IFC activities \& Section News}

$\square$ find Working Group contacts

$\square$ read CIF/IFC Position Papers

$\square$ learn about Continuing Education Opportunities

$\square$ explore Job Opportunities

$\square$ become a member

$\square$ view links to other sites

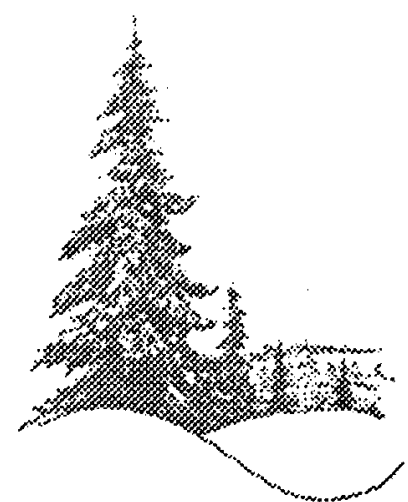




\section{Tree Canada Launches BC Fire Releaf to Replace Destroyed Trees}

The President of the Tree Canada Foundation, Jeff Monty, announced the establishment of BC Fire ReLeaf, a fund to help the beleaguered people of British Columbia recover from the devastating 2003 wildfires.

"The return of trees to a community is an important step in the return to a more normal life," he said. "We want to help the fire-ravaged communities of $\mathrm{BC}$ return as quickly as possible to the beautiful environment they had before the fires hit," he said.

Tree Canada has previously helped the communities of Saguenay, Quebec during the floods in 1996; eastern Ontario, Quebec and New Brunswick after the Ice Storms of 1998; and the people of
Saskatchewan, whose urban tree losses to Dutch Elm Disease warranted the planting of other species from 2000 to the present.

Although wildfire has always been a part of Canadian forests, the $\mathrm{BC}$ fires of 2003 were particularly damaging because so many of them occurred in close proximity to people. At their peak, over 30000 people were evacuated from such communities as Kamloops, Kelowna and Falkland. Communities such as Louis Creek and Barriere saw tremendous losses. Estimates are that insurance claims will easily exceed \$100 million. Unfortunately many people either do not have insurance or landscaping items such as trees are not covered.
"We appreciate the support that the Tree Canada Foundation is offering the people of this area," said Joe Creron, Parks Manager for the City of Kelowna, "We look forward to implementing the Foundation's BC Fire ReLeaf program so that we can rehabilitate the landscape of this beautiful area".

Individual and corporate donations to BC Fire ReLeaf can be made directly through the Foundation's Web site www.tcffca.ca or through their office at 220 Laurier Ave. W., Ottawa, ON K1P 5Z9.

For further information please contact: Jeff Monty, Tree Canada (613) 567-5545

\section{Home Depot Plants 100 Trees to Mark 100th Store Established in Thunder Bay}

Home Depot marked the opening of their 100th store in Canada with the planting of 100 trees in the Soroptimist International Garden (Victoria Avenue between Waterloo and Tarbutt Streets) in Thunder Bay, Ontario on Saturday, October 4, 2003. The planting was facilitated by the Tree Canada Foundation in partnership with the City of Thunder Bay and Trees Thunder Bay.

"The success of Home Depot is based on us working with communities with the environment in mind," said Rick Schweyer, Store Manager. "The opening of our 100th Canadian store in conjunction with the planting of 100 trees for the people of Thunder Bay is a perfect match."

Since 1998, Home Depot has partnered with the Tree Canada Foundation to replace trees lost in the 1998 Ice Storm, schoolyard greening and other large-scale community naturalization projects. The Thunder Bay project will feature 100 trees-both coniferous and deciduous, planted in a park well known for its theme of international cooperation.

"We are proud of clean, green Thunder Bay," said Mayor Ken Boshcoff. "We appreciate the efforts of Home Depot, Tree Canada and Trees Thunder

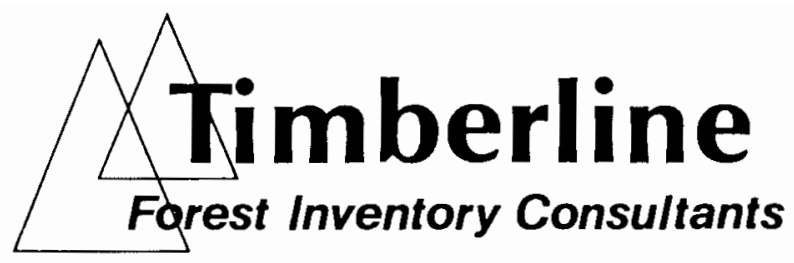

A CIF/IFC Corporate Sustaining Member

Bay in helping us continue to make Thunder Bay, 'Superior by Nature'.”

Tree planting began with a recognition ceremony featuring Mayor Boshcoff and other dignitaries. Planting was done by employees and spouses from the Home Depot store as well as volunteers from Trees Thunder Bay, a local citizen's group active in protecting and maintaining the area's trees.

The Tree Canada Foundation is a not-for-profit charitable organization established to encourage Canadians to plant and care for trees in urban and rural environments with the goal of helping reduce the harmful effects of carbon dioxide emissions. To date the Foundation has engaged more than 60 top Canadian companies and government agencies to support the planting of over 75 million trees, the regreening of over 300 schoolyards, five national urban forestry conferences and other efforts to sensitize Canadians to the benefits of planting and maintaining trees.

For further information: Karen Lewis, City of Thunder Bay - (807) 625-3859 Michael Rosen, Tree Canada Foundation (613) 290-3665 (cellular) 


\section{Green Streets Canada to Help Urban Forests!}

The President of the Tree Canada Foundation, Jeff Monty, has announced the launch of the 2004 version of Green Streets Canada, the largest nation-wide urban forestry program.

"Urban forests are important to the $80 \%$ of Canadians who live in urban areas," he said. "With greater pressures on these forests, we are trying to provide incentives to municipalities to manage them in a sustainable manner to ensure our future air and water quality."

The program contributes a minimum 50/50 funding through a competitive process based on population size. Municipalities are being asked to put forward proposals on behalf of their communities based on inventory, tree planting, maintenance and education.
Over 280 Canadian communities have been greened under the program since 1994 with almost \$2 million in funding being committed to municipal trees. This year's program will award municipalities with funding to help in tree inventory, tree planting, maintenance activities (such as watering and pruning) as well as tree and forest education.

The Canadian Forest Service (CFS), a sector within Natural Resources Canada, is a major sponsor of the Tree Canada Foundation and its many programs, including Green Streets Canada. Through programs such as this, and with the support of the CFS and its other sponsors, Tree Canada helps focus attention on the increasing importance of urban forestry throughout Canada.
The Federation of Canadian Municipalities (FCM) also endorses the program. In addition, delegates to FCM's 2004 Sustainable Communities National Conference and Trade Show, to be held in Ottawa February 4-7, 2004, have the option of purchasing carbon offsets to reduce the impact of their conference travel. FCM will forward these purchases to the Tree Canada Foundation to support tree planting projects. For more information about FCM and the Conference, please visit the Sustainable Communities Knowledge Network at: http://kn.fcm.ca.

For further information including an application please contact: www.tcffca.ca. Michael Rosen, Tree Canada Foundation (613) 290-3665 (cellular)

\section{Tree Canada Launches Maritime Hurricane Releaf to Replace Destroyed Trees}

The President of the Tree Canada Foundation, Jeff Monty has announced the establishment of Maritime Hurricane ReLeaf, a fund to help the people of Nova Scotia and Prince Edward Island recover from the devastation caused by Hurricane Juan during September 28 and 29, 2003.

Packing winds of over $150 \mathrm{~km} /$ hour the hurricane was responsible for the deaths of two people and deprived another 300000 of electricity for up to a week. One of the most visible effects of the storm was the downing of tens of thousands of trees in Halifax, Truro, New Glasgow, Charlottetown and many other Maritime towns. Canadians, including ex-Maritimers as well as corporations have been contacting the Foundation to ask how they can become involved in the recovery.

"The loss of trees many of which were older and lent a unique character to these Maritime communities is a terrible loss," said Jeff Monty, "Our Foundation is pledged to help the people and the urban forest recover from this incredible devastation," he said.

The storm went directly over Halifax. As a first port of entry for many immigrants to Canada, and as one of Canada's best forested cities, the loss of its trees is particularly sad. "The loss of a number of rare specimen trees includ- ing a 14-foot-diameter European beech dating back 160 years is particularly tragic," said Stephen King a well known Canadian parks and urban forest manager who works for the Halifax Regional
Municipality. "We are very grateful that the people of Canada and the Tree Canada Foundation are stepping forward to help our urban forests in a time of great need,' he said.

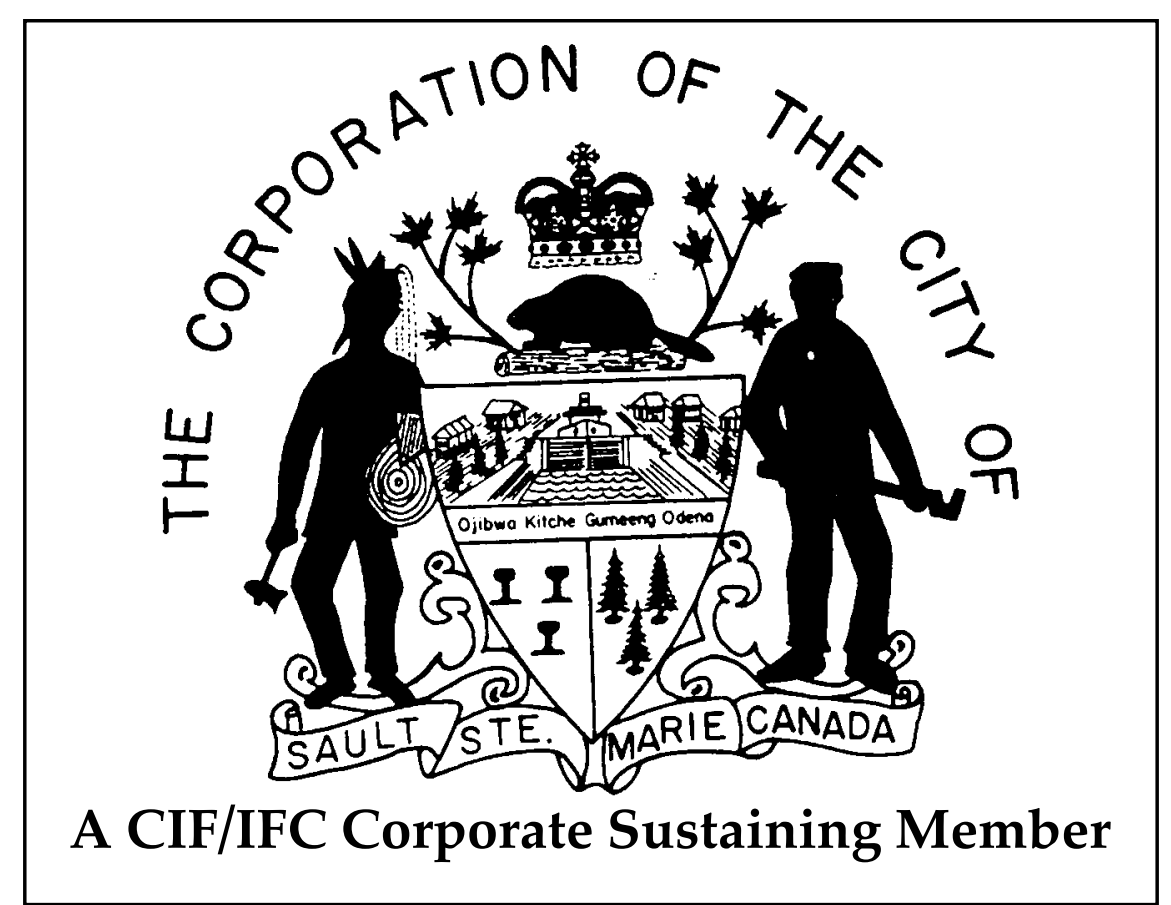

